\title{
Acquired Ichthyosis Triggered by an Osseous Hemangiopericytoma: A Case Report and Review of the Literature
}

\author{
Aikaterini Patsatsi $^{a} \quad$ Aikaterini Kyriakou $^{a}$ Vasilios Karavasilis $^{b}$ \\ Fragkiski Tsatsou $^{\mathrm{a}}$ Georgios Lazaridis $^{\mathrm{b}}$ Dimitrios Kalabalikis $^{\mathrm{a}}$ \\ Dimitrios Sotiriadis ${ }^{a}$ \\ ${ }^{\mathrm{a}} 2$ nd Department of Dermatology and Venereology, and ${ }^{\mathrm{b}}$ Department of Medical \\ Oncology, Aristotle University School of Medicine, Thessaloniki, Greece
}

\section{Key Words}

Acquired ichthyosis $\cdot$ Hemangiopericytoma $\cdot$ Paraneoplastic skin disease

\begin{abstract}
Ichthyoses are a heterogeneous group of cutaneous keratinization disorders that can be congenital or acquired. Apart from neoplastic disorders, the acquired form of ichthyosis (AI) has been associated with a variety of diseases including infections, autoimmune/inflammatory and endocrine/metabolic diseases as well as nutritional conditions, medications and others. However, malignancy accounts for half of the reported cases, most commonly including lymphoproliferative disorders. We present a case of AI as a paraneoplastic skin manifestation of a primary, osseous hemangiopericytoma (HP) accompanied by multiple liver metastases. We also review the literature and discuss the necessity of investigating underlying diseases, especially malignancy, when adult-onset ichthyosis arises.
\end{abstract}

(C) 2014 S. Karger AG, Basel

\section{Introduction}

Ichthyoses are a heterogeneous group of cutaneous keratinization disorders that can be congenital or acquired and are clinically distinguished by dry, rough skin with prominent scaling [1]. The term ichthyosis is derived from the ancient Greek root 'ichthys', meaning fish, and describes the resemblance of the skin in this condition to the fish scales. The 
Patsatsi et al.: Acquired Ichthyosis Triggered by an Osseous Hemangiopericytoma: A Case Report and Review of the Literature

acquired form of ichthyosis (AI) may be the result of a malignant disease, a nonmalignant disease or a drug reaction [1,2]. Malignancy represents half of the reported cases, most commonly including lymphoproliferative disorders [2]. Hemangiopericytoma (HP) is a malignant tumor that is derived from the pericytes of Zimmerman $[3,4]$. Due to its vascular origin, HP can arise in any part of the body, with the vast majority occurring in the soft tissue [4-6]. However, primary HP of the bone is very rare [5, 6]. We present a case of AI as a paraneoplastic skin manifestation of a primary, osseous HP, accompanied by multiple liver metastases, an association that, to our knowledge, has not been previously reported.

\section{Case Report}

A 34-year-old woman presented to our Department with a 2-month history of a widespread, scaling, skin eruption. She also complained of a 7-kg weight loss over the last 2 months as well as fatigue and low back pain. On physical examination, she had generalized xerosis with large rhomboidal scales covering most of her body and scalp, painful stomatitis and palmar and plantar hyperkeratosis (fig. 1a-d). Bilateral ectropion due to eyelid involvement was present. There was no personal or family history of ichthyosis. A skin biopsy was performed, which confirmed the clinical diagnosis of AI by revealing hyperorthokeratosis and an absence of granular layers (fig. 2a). However, her past medical history was significant for osseous HP, for which she had successfully undergone tumor embolization, followed by a total tumor resection 2 years ago. Based on her past medical history and the current signs, a possible recurrence of HP was suspected, and therefore, an abdominal computed tomography (CT) scan was recommended. The CT scan revealed a multilobular tumor mass in the minor pelvis, infiltrating the sacrum and perirectal space and spreading to the lower lumbar muscles (HP recurrence) (fig. 2b). The presence of multiple liver metastases was also reported. Intensive topical emollients were prescribed for the AI, and the patient was referred to the Oncology Department. Treatment with paclitaxel at a dose of 80 $\mathrm{mg} / \mathrm{m}^{2}$ at days 1,8 and 15 , followed by 1 week of rest and repeated every 4 weeks. Unfortunately, despite the chemotherapy, no improvement of either the tumor mass and metastases or the AI was observed over the following 3 months. On the contrary, at that point, the patient's general condition started to deteriorate rapidly. The patient passed away 6 months after her initial presentation.

\section{Discussion}

HP was introduced by Stout and Murray [3] in 1942 as one of the first peripheral tumors to be described in the soft tissue. It is derived from the pericytes of Zimmerman, which are pericapillary mesenchymal cells with a contractile ability $[3,4]$. Owning to its vascular origin, HP can arise in any part of the body; however, the vast majority of these tumors occur in the soft tissue [4-6]. HP of the bone is very rare, accounting for $0.1 \%$ of malignant primary bone tumors and $11 \%$ of malignant vascular bone tumors $[5,6]$. It predominantly occurs in the fourth and fifth decade of life, as a palpable mass accompanied by pain, with a male-tofemale ratio of 1.8:1 [5, 6]. HP is a slow-growing, but malignant tumor with a capacity for local invasion and known for spreading through the bloodstream [6]. Therefore, this rare neoplasm, which frequently presents unpredictable behavior, is capable of both local recurrence and distant metastasis, and a close follow-up is strongly recommended [6]. 
AI clinically resembles vulgar ichthyosis, with cutaneous xerosis and a great quantity of rhomboid scales, similar to fish scales [1]. The colors of the scales as well as their diameter vary [1]. It most commonly appears in the elderly, affecting mainly the extensor regions of the upper and lower limbs and trunk [1]. Histologically, both AI and ichthyosis vulgaris usually present with identical features, typically with mild compact hyperorthokeratosis, reduced or absent granular layers and a reduced rete-papilla pattern.

The first step in evaluating an adolescent or adult with new-onset ichthyosis is differentiating AI from other causes of new-onset ichthyosis, such as late-onset ichthyosis vulgaris, xerosis and Refsum's disease, which is an autosomal recessive disease, characterized by sensory neuropathy, ataxia, decreased visual acuity, retinitis pigmentosa and ichthyosis [1]. Therefore, an algorithm for the evaluation of such patients has been proposed [1]. All other hereditary forms of ichthyosis are not considered in the differential diagnosis since they essentially present before the age of 13 . Once the diagnosis of AI is established, the underlying cause needs to be revealed.

Apart from neoplastic disorders, AI has been associated with a variety of diseases including infections, autoimmune/inflammatory and endocrine/metabolic diseases as well as nutritional conditions, medications and others (table 1) [1, 2, 7-15]. However, malignancy accounts for half of the reported cases [2], most commonly Hodgkin's disease, representing about $70 \%$ of the cases $[1,7,12-15]$.

AI may occur either before or after the identification of the underlying disease [1, 12, 14], and its severity and course depends on the course of the internal disease [1, 15]. Paraneoplastic AI rarely occurs as the only manifestation of the associated disease. It is usually accompanied by weight loss, fatigue and lymphadenopathy [2]. In most cases, response to therapy for the underlying disorder leads to regression of the ichthyotic lesions $[1,8,15]$. However, hydration, lubrication and keratolysis are of great use in improving dryness and scaling [1]. Keratolytic agents include salicylic acid, urea, propylene glycol and lactic acid, while hydration may be accomplished by the use of humectants, such as lactic, glycolic and pyruvic acids [1].

The pathophysiological mechanisms responsible for paraneoplastic ichthyosis remain unclear. Ichthyosis occurs when there is a disruption in the process of cornification, which is complex and involves multiple enzymes. Cooper et al. [16] suggested impaired epidermal lipogenesis as the mechanism of the cutaneous changes in AI. Transforming growth factor alpha, produced by tumor cells, has also been implicated in the pathogenesis of paraneoplastic AI $[2,7]$. Last, when associated with lymphoproliferative disorders, the deficiency is likely to be related to poor vitamin A absorption [1,12-14].

In our AI case, the underlying malignancy had already evolved to a fatal metastatic status, and the disrupted cornification could not respond to any skin-directed topical therapies, mainly emollients.

In conclusion, adult-onset ichthyosis should alert the clinician to an underlying disease and make further investigation necessary (especially for malignancy).

\section{References}

1 Patel N, Spencer LA, English JC III, Zirwas MJ: Acquired ichthyosis. J Am Acad Dermatol 2006;55:647-656.

-2 Levy 0, Tishler M: Acquired ichthyosis as the primary manifestation of renal cell carcinoma. Isr Med Assoc J 2009;11:121-122.

-3 Stout AP, Murray MR: Hemangiopericytoma: a vascular tumor featuring Zimmermann's pericytes. Ann Surg 1942;116:26-33.

4 Kuhn C III, Rosai J: Tumors arising from pericytes. Ultrastructure and organ culture of a case. Arch Pathol 1969;88:653-663. 
Patsatsi et al.: Acquired Ichthyosis Triggered by an Osseous Hemangiopericytoma: A Case Report and Review of the Literature

5 Lian YW, Yao MS, Hsieh SC, Lao WT, Fang CL, Chan WP: MRI of hemangiopericytoma in the sacrum. Skeletal Radiol 2004;33:485-487.

6 Zentar A, Sall I, Ali AA, Bouchentouf SM, Quamous M, Chahdi H, Hajjouji A, Fahssi M, El KH, Al BA, Marjani M, Sair K, Bousselmame N: Sacral hemangiopericytoma involving the retrorectal space: report of a case. Surg Today 2009;39:344-348.

7 Akpinar TS, Ozkok A, Bakkaloglu OK, Saka B: Acquired ichthyosis as a presenting finding of Hodgkin's lymphoma. Int J Hematol 2012;96:401-402.

-8 Ameen M, Chopra S, Darvay A, Acland K, Chu AC: Erythema gyratum repens and acquired ichthyosis associated with transitional cell carcinoma of the kidney. Clin Exp Dermatol 2001;26:510-512.

-9 Biver-Dalle C, Gil H, Meaux-Ruault N, Mermet-Ginet I, Aubin F, Humbert P, Magy-Bertrand N: Acquired ichthyosis and livedoid palmoplantar keratoderma: two unusual skin manifestations of systemic lupus erythematosus (in French). Rev Med Interne 2012;33:e14-e16.

10 Ennibi K, Rabhi M, Al BA, Bahrouch L, Boudlal M, Zinebi A, Akhouad Y, Berady S, Chaari J, Toloune F: Acquired ichthyosis revealing an Hodgkin's disease (in French). Rev Med Interne 2008;29:418-420. Menni S, Boccardi D, Brusasco A: Ichthyosis revealing coeliac disease. Eur J Dermatol 2000;10:398-399. Pipkin CA, Lio PA: Cutaneous manifestations of internal malignancies: an overview. Dermatol Clin 2008;26:1-15, vii.

13 Rabhi M, Ennibi K, Harket A, Al BA, Labraimi A, Chaari J, Toloune F: Acquired ichthyosis disclosing nonHodgkin's malignant lymphoma. Intern Med 2007;46:397-399.

14 Ramos-E-Silva, Carvalho JC, Carneiro SC: Cutaneous paraneoplasia. Clin Dermatol 2011;29:541-547.

-15 Tsochatzis E, Vassilopoulos D, Deutsch M, Asvesti C, Sevastos N, Archimandritis AJ: Myelodysplastic syndrome presenting as acquired ichthyosis. Eur J Intern Med 2006;17:368-369.

16 Cooper MF, Wilson PD, Hartop PJ, Shuster S: Acquired ichthyosis and impaired dermal lipogenesis in Hodgkin's disease. Br J Dermatol 1980;102:689-693.

Table 1. Malignant and nonmalignant diseases reported with AI and considered in the differential diagnosis

Malignancies

Hodgkin's disease, non-Hodgkin's lymphomas (ALCL), mycosis fungoides, cutaneous T-cell lymphoma, lymphomatoid papulosis, small bowel lymphoma, ATL (adult T cell leukemia/lymphoma), multiple myeloma, myelodysplastic syndrome, polycythemia vera, malignant histiocytosis, POEMS syndrome, leiomyosarcoma, reticulo-lymphosarcoma/reticulum cell sarcoma, Kaposi's sarcoma, rhabdomyosarcoma, granulocytic sarcoma, spindle cell sarcoma, malignant melanoma, ovary carcinoma, cervix carcinoma, renal cell carcinoma, breast carcinoma, bronchial carcinoma, laryngeal carcinoma, esophageal carcinoma, gastric carcinoma, hepatocellular carcinoma, bladder carcinoma, transitional cell carcinoma of kidney

\begin{tabular}{ll}
\hline Infectious diseases & HIV, HTLV-I, HTLV-II, leprosy \\
\hline $\begin{array}{l}\text { Autoimmune/ } \\
\text { inflammatory diseases }\end{array}$ & $\begin{array}{l}\text { Systemic lupus erythematosus, dermatomyositis, eosinophilic fasciitis, graft- } \\
\text { versus-host disease, sarcoidosis }\end{array}$ \\
\hline $\begin{array}{l}\text { Endocrine/ } \\
\text { metabolic diseases }\end{array}$ & $\begin{array}{l}\text { Chronic hepatic dysfunction, chronic renal failure, hypothyroidism, hyperparathy- } \\
\text { roidism, hypopituitarism, diabetes mellitus }\end{array}$ \\
\hline Nutritional diseases & $\begin{array}{l}\text { Malnutrition, malabsorption, gross nutritional deficiency, celiac disease, } \\
\text { pancreatic insufficiency, essential fatty acid deficiency }\end{array}$ \\
\hline Medications & $\begin{array}{l}\text { Cimetidine, clofazimine, hydroxyurea, cholesterol-lowering agents, nicotinic acid, } \\
\text { 3-hydroxy-3-methylglutaryl coenzyme A reductase inhibitors, triparanol, } \\
\text { allopurinol, butyrophenones }\end{array}$ \\
\hline Others & Sympathectomy, Down syndrome, bone marrow transplant
\end{tabular}


Patsatsi et al.: Acquired Ichthyosis Triggered by an Osseous Hemangiopericytoma: A Case Report and Review of the Literature

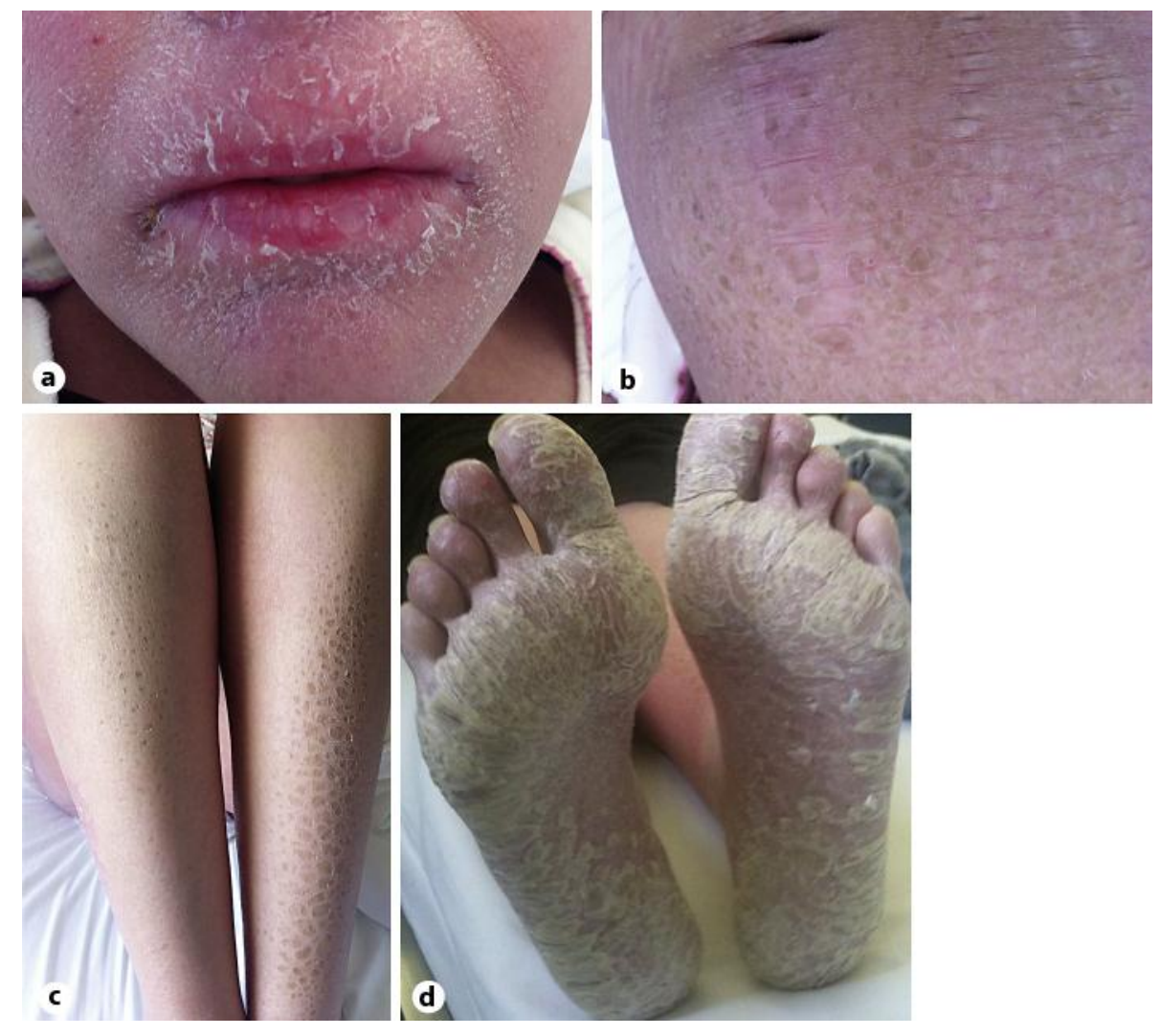

Fig. 1. a Facial skin xerosis. b Large rhomboidal scales covering most of the body. c Dry skin with rhomboidal scales on the lower extremities. $\mathbf{d}$ Plantar hyperkeratosis. 
Case Rep Dermatol 2014;6:10-15

DOI: $10.1159 / 000358294$

Patsatsi et al.: Acquired Ichthyosis Triggered by an Osseous Hemangiopericytoma: A Case Report and Review of the Literature
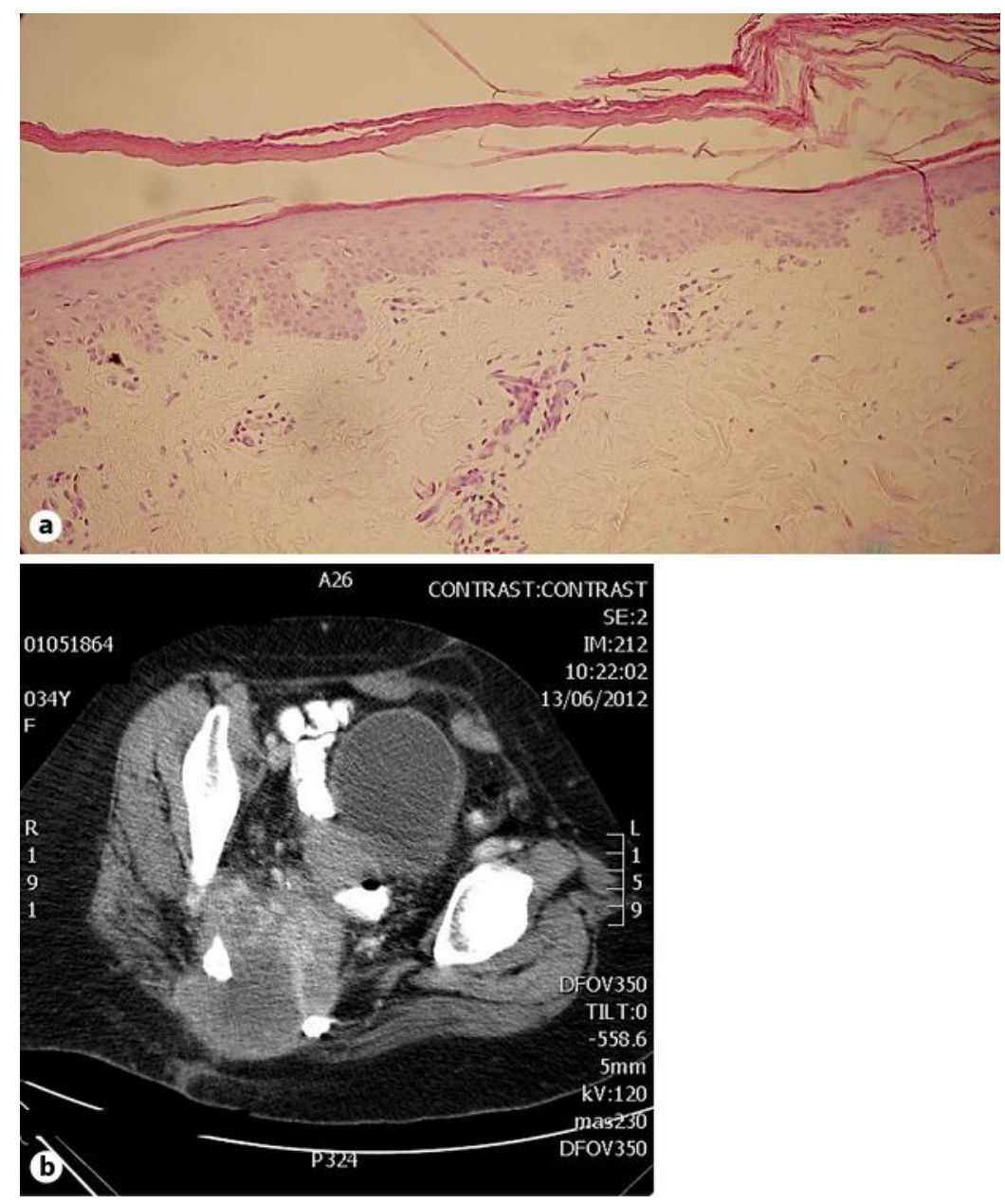

Fig. 2. a Hyperorthokeratosis, absence of granular layer and reduced rete-papilla pattern (HE, $\times 40)$. b Osseous HP. 